\title{
TOPOGRAPHIC DISTRIBUTION OF LARYNGEAL CANCER
}

\author{
K. R. Shaikh
}

\begin{abstract}
OBJECTIVE:To determine the topographical distribution and extent of disease in cases of carcinoma larynx treated in our set up and to compare it with similar studies conducted at other centres.

SETTING: Department of ENT (Unit II), Liaquat University Hospital Hyderabad, Sindh - Pakistan from January 1999 to May 2003.

METHODS: This study included one hundred cases of carcinoma larynx. Separate proforma for each patient was filled to collect data. Proforma included variables such as personal data, habits, findings on clinical examination, endoscopic findings, and histopathological and radiological reports.

RESULTS: One hundred cases of carcinoma larynx were included in this study. Age of the patients varied from 19 to 80 years, but majority of patients belonged to age group between 40 to 60 years. Majority of cases i.e. 92 were male while others female. Male to female ratio was 11:1. The majority of cases belonged to lower socioeconomic class (80\%). Most of the male patients were smokers. There were $56 \%$ supraglottic, $34 \%$ transglottic and $10 \%$ glottic tumours. According to the TNM classification of UICC, $54 \%$ patients belonged to stage IV, followed by $25 \%$ of stage III, $14 \%$ of stage II and $7 \%$ of stage I.

CONCLUSIONS:This study found that majority of patients were male, between 40 to 60 years of age and smokers. Male to female ratio was 11:1 Squamous cell carcinoma was the most common followed by tranglottic tumor, while pure glottic involvement was less common as compared to other studies.
\end{abstract}

KEY WORDS:Carcinoma larynx. Staging. Topographic distribution.

\section{INTRODUCTION}

Larynx is the most common site of Head and Neck Cancers in United States. In a report from the National Cancer Database laryngeal carcinoma accounts for $21 \%$ of the cases. ${ }^{1}$ William M. Manden Hall in his study has reported laryngeal cancer as most common head and neck cancer excluding skin cancer. ${ }^{2}$ While, Thapa has reported incidence of laryngeal tumours only second to thyroid neoplasm among the head and neck tumour where all the laryngeal tumours were squamous cell cancinonia. ${ }^{3}$ In a multicentric study conducted by Pakistan Medical Research Council and Cancer Registry Sindh, laryngeal cancer has been listed in top ten head and neck cancers. Glottic tumours are often discovered at an earlier stage because hoarseness of voice tend to occur relatively early in the coarse of the disease. Supraglottic cancers are often discovered late and present with airway obstruction or palpable neck nodes. Primary subglottic tumours are rare and typically presents with stridor and complains of dyspnoea on exertion. Biological behaviors also vary location. ${ }^{4}$ Supraglottic cancer is richly supplied with lymphatic leading to high fre- quency of cervical nodal mestastasis. The lymphatic drainage of right and left sides of the supraglottic and sub glottic larynx are separate. This knowledge allows prediction of metastatic behavior. In comparison, true vocal cord (glottic larynx) possess little or no lymphatic drainage. Incidence of carcinoma of larynx is strongly related to cigarette smoking. Reduction in smoking has been associated with reduced incidence of laryngeal cancer. ${ }^{1-5}$ Other factors associated with an increased risk of laryngeal cancer include alcohol abuse, ${ }^{6-7}$ prolonged exposure of fossil fuel used in single stove, ${ }^{8}$ lower socio-economic class, ${ }^{7}$ laryngeal papillomatosis, ${ }^{9-10}$ passive smoking and occupational exposure to substance, such as asbestos and nikel. ${ }^{10}$ High dietary intake of fruit and vegetables is associated with decreased incidence of laryngeal cancer, possibly because of protective effect related to high contents of vitamin $A$ and $C .{ }^{6,7,10}$ Almost all laryngeal cancers originate from the surface epithelium and are squamous cell carcinoma or its variant; most are well and moderately differentiated. Verrucous carcinoma is characterized by locally aggressive behavior and slow growth. This tumour accounts for 1 to 2\% laryngeal 
carcinonia. Basiloid squamous cell carcinoma is another variant of squamous cell carcinoma. It is in infrequent, more aggressive and has worse prognosis. Non squamous tamours of larynx account for less than $50 \%$ of laryngeal tumours. They typically arise from salivary tissue or neuro-endrine cells within larynx. Through this paper, we present our experience with laryngeal cancer in our set up.

\section{PATIENTS AND METHODS}

Hundred cases of carcinoma larynx were studied to find out the topographical distribution and extent of disease in cases treated at ENT department of Liaquat University Hospital Hyderabad Sindh - Pakistan. Permission was taken form departmental committee to use patient's data. Separate proforma for each patient was filled containing patient's history, habits, findings on clinical examination (IDL and neck examinations), endoscopy and radiological investigations (X-ray neck and chest). All new patients with history of change in voice and difficulty in breathing for more than 6 weeks were examined and patients showing positive clinical finding on IDL or those where indirect laryngosocpy was not possible were kept for direct laryngoscopy. Direct laryngoscopy was done using rigid endoscope under general anaesthesia, biopsies were taken, site and extent of the disease was noted. Those cases with positive histopathological report for squamous cell carcinoma or its variant were included in the study.

\section{RESULTS}

Among one hundred cases included in the study, 92 were males and 8 females with male to female ratio of 11:1. Age of patients varied from 19 to 80 years but majority belonged to age group between $40-60$ years while $84 \%$ of these patients were smoker. There were $56 \%$ supraglottic and $34 \%$ transglottic tumours. Ninety-nine cases were having squamous cell carcinoma while one was reported as varruscus carcinoma, a variant of squamous cell carcinoma (Figure I). There were $68 \%$ cases of well differentiated, $24 \%$ poorly differentiated and $7 \%$ moderately differentiated squamous cell carcinonia (Figure II). According to TNM classification, $54 \%$ cases belonged to stage IV while $25 \%$ were of stage III, followed by $14 \%$ patient of stage II and $7 \%$ of stage-I.
FIGURE I:

DISTRIBUTION OF TUMORS ACCORDING TO THE SITE OF INVOLVEMENT

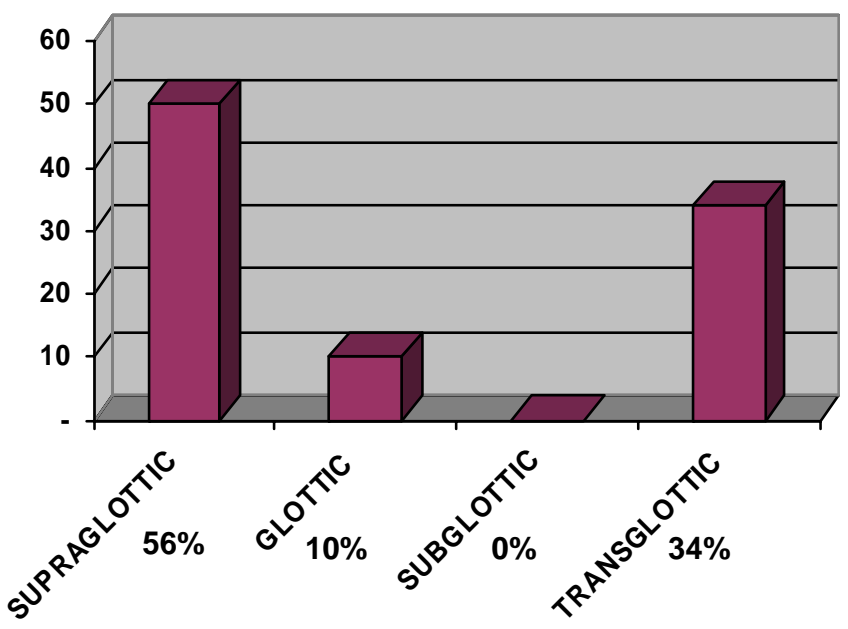

FIGURE II:

HISTOPATHALOGICAL FINDINGS OF TUMORS

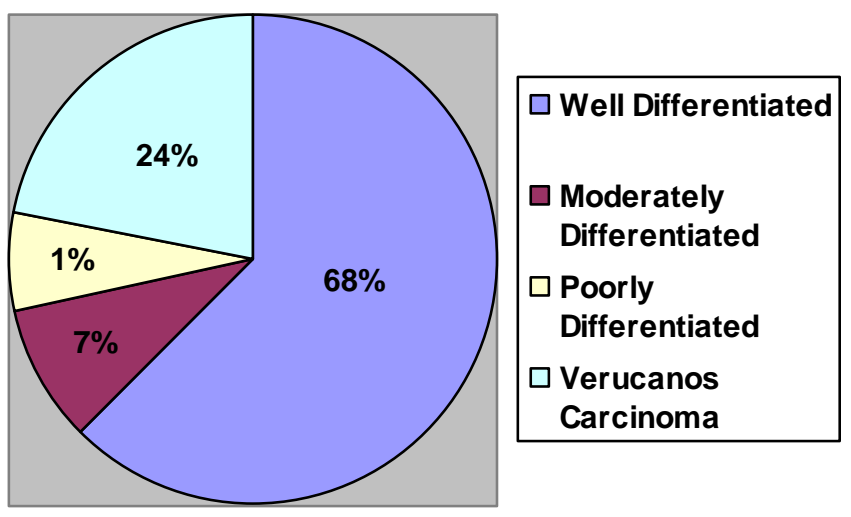

\section{DISCUSSION}

The topographical distribution of laryngeal cancer among the compartments of larynx shows geographical variation. In this study, majority of cancers were of supraglottic larynx while the second biggest group was of transglottic tumor with wide extent of laryngeal involvement followed by third group of glottic cancers. In USA, glottic cancers are more frequent whereas most cases in the Mediterranean countries are supraglottic. ${ }^{11}$ One study conducted in Finland Shows distinct increase in glottic to supraglottic incidence ratio from 5:1 to 1.9:1 in males. ${ }^{12}$ However, study conducted by Zaidi SH has recommended total laryngectomy as the most effective mode of treatment in patients of squamous cell carcinoma. It indicates the wide extent of laryngeal involvement ${ }^{13}$ as in present study. In another study conducted by Javed Aslam, $56 \%$ tumours were glottic, while $36 \%$ supraglottic and 
only $8 \%$ were transglottic. ${ }^{14}$ It may be due to selection of only stage specific cases in their study.

\section{CONCLUSION}

This study has found highest incidence of supraglottic tumours (56\%) in our set up, followed by transglottic tumours (34\%) and only $10 \%$ cases with glottic tumours. As compared to other studies done in Pakistan and abroad, it seems that patients present with very advance disease at the time of diagnosis. Therefore, there is dire need of improvement in access of medical facilities by the general population and continuous medical education of family practitioners, where these patients first report.

\section{REFERENCES}

1. Hoffman HT, Karnell LH, Funk GF, Robinson RA, Menck HR. The National Cancer Data Base report on cancers of the head and neck. Arch Otolaryngol Head Neck Surg. 1998;124(9):95162.

2. Mendenhall WM, Million RR, Stringer SP, Cassisi NJ. Squamous cell carcinoma of the glottic larynx: a review emphasizing the University of Florida philosophy. South Med J. 1999;92(4):385-93.

3. Thapa N, Jha AK, Rijal JP, Shah A. Study on head and neck tumours presented in ENT OPD of Nepal Medical College Teaching Hospital. Nepal Med Coll J. 2003;5(2):79-81.

4. Raitiola H, Pukander J, Laippala P. Glottic and supraglottic laryngeal carcinoma: differences in epidemiology, clinical characteristics and prognosis. Acta Otolaryngol. 1999;119(7):847-51.
5. Hiranandni LH. Panel on epidemiology and etiology of laryngeal carcinoma. Laryngoscope. 1975; 85(7):1197-207.

6. Maier H, Tisch M: Epidemiology of laryngeal cancer results of the Heidelberg case control study. Acta Otolaryngol Suppl. 1997; 527; 160-4.

7. Xing G, Meihna C, Shengzhang F. A case control study of etiology of laryngeal cancer in Liaoning province. Med J. 1995; 108:373-350.

8. Dietz A, Sennweld E, Maier H. Indoor air pollution by emission of fossil fuel single stones possibly a hitherto underrated risk factor in the development of carcinomas in the head and neck. Otolaryngol Head Neck Surg. 1995; 112:308-15.

9. Pou AM, Rimell FL, Jordan JA. Adult respiratory papillosmatosis human papilloma virus type and viral coinfection as predicator of prognosis. Ann Otol Rhinolaryngol. 1995; 104: 758-62.

10. Koufman JA, Bruke AJ. The etiology and pathogenesis of laryngeal carcinoma. Otolaryngol Clin North Am. 1997; 30:1-17.

11. Basut O, Tezel I, Erisenl L, Coskum H. Topographic distribution of laryngeal cancer. J Environ Pathol Toxicol Oncol. 1996; 15 (2-4): 231-2.

12. Raitiola HS, Pukander JS. Chaning trends $n$ the incidence of laryngeal cancer. Acta Oncol. 1997; 36 (1): 33-6.

13. Ahmed Z, Aslam J, Zaidi SH. Laryngeal cancer surgery techniques, management and complications. Pak J Otolaryngol. 2003; 19(4): 41-3.

14. Aslam J, Ahmed Z, Azeem M, Malik A, Ahmed I. Complications of total layrngectomy. Pak J Med Sci. 2006; 22: (1): 33-37.

\begin{tabular}{|l|}
\hline AUTHOR AFFILIATION: \\
Dr. K. R. Shaikh \\
Assistant Professor, ENT Department \\
Liaquat University of Medical \& Health Sciences \\
Jamshoro, Sindh - Pakistan.
\end{tabular}

